\title{
Efeitos do cádmio na anatomia e na fotossíntese de duas macrófitas aquáticas
}

\author{
Vânia Lima Souza ${ }^{1}$, Delmira da Costa Silva ${ }^{1,2}$, Kaline Benevides Santana ${ }^{1}$, Marcelo Schramm Mielke ${ }^{1}$, \\ Alex-Alan Furtado de Almeida ${ }^{1}$, Pedro Antonio Oliveira Mangabeira ${ }^{1}$ e Emerson Antônio Rocha ${ }^{1}$
}

Recebido em 30/07/2007. Aceito em 15/07/2008

\begin{abstract}
RESUMO - (Efeitos do cádmio na anatomia e na fotossíntese de duas macrófitas aquáticas). As macrófitas aquáticas vêm sendo usadas no monitoramento de águas poluídas por metais pesados, dessa forma, avaliou-se a capacidade fitorremediadora de Alternanthera philoxeroides (Mart.) Griseb. (Amaranthaceae) e de Polygonum ferrugineum Wedd. (Polygonaceae). As duas espécies foram submetidas as concentrações 0,25 e $50 \mathrm{mg} \mathrm{L}^{-1}$ de cádmio em solução nutritiva. Aos sete dias após a aplicação dos tratamentos, foram efetuadas medições de trocas gasosas foliares e de emissão de fluorescência da clorofila em folhas expandidas e maduras. Amostras de raiz, caule e folha foram fixadas em FAA 70, incluídas em historresina, seccionadas em micrótomo rotativo e submetidas a coloração com azul de toluidina a $1 \%$. Determinou-se o teor de Cd nas amostras vegetais utilizando ICP-MS. Na nervura central da folha e na raiz de

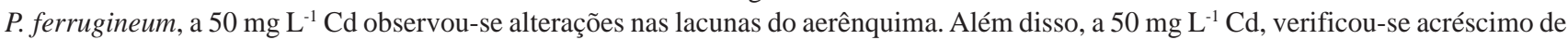
tricomas glandulares nas folhas e compactação do mesofilo. No caule de A. philoxeroides, a $50 \mathrm{mg} \mathrm{L}^{-1} \mathrm{Cd}$, os núcleos das células do córtex apresentaram formato elíptico e a 25 e $50 \mathrm{mg} \mathrm{L}^{-1} \mathrm{Cd}$, ocorreu diminuição de drusas em células da nervura central da folha. Os teores de Cd para A. philoxeroides foram maiores na raiz, seguido do caule e da folha. A taxa de fotossíntese líquida de P. ferrugineum foi mais afetada pelo Cd em comparação a A. philoxeroides. Não houve variação da atividade do fotossistema II (Fv/Fm) entre as duas espécies e os tratamentos com $\mathrm{Cd}$. A. philoxeroides foi mais tolerante ao $\mathrm{Cd}$ do que $P$. ferrugineum, o que indica sua potencialidade para uso em programas de fitorremediação.
\end{abstract}

Palavras-chave: Alternanthera philoxeroides, fluorescência da clorofila, metal pesado, Polygonum ferrugineum

ABSTRACT - (Effects of cadmium on the anatomy and photosynthesis of two aquatic macrophytes). Aquatic macrophytes have been used to monitor waters polluted by heavy metals. The phytoremediation capacity of Alternanthera philoxeroides (Mart.) Griseb. (Amaranthaceae) and Polygonum ferrugineum Wedd. (Polygonaceae) was therefore evaluated. These two species were submitted to treatments of 0,25 and $50 \mathrm{mg} \mathrm{L}^{-1} \mathrm{Cd}$ in nutritive solution. Seven days after treatment application, leaf gas exchange and chlorophyll fluorescence were measured in mature and fully expanded leaves. Fragments of roots, shoots and leaves were fixed in FAA 70, embedded in historesin and cut with a rotating microtome, and the sections stained with $1 \%$ toluidine blue. The Cd content in plant biomass was determined using ICP-MS. In P. ferrugineum exposed to 25 and $50 \mathrm{mg} \mathrm{L}^{-1} \mathrm{Cd}$, an increase in the central leaf-vein- and root-aerenchyma lacunae was observed. Furthermore, in plants exposed to $50 \mathrm{mg} \mathrm{L}^{-1} \mathrm{Cd}$, an increase in leaf glandular trichomes and mesophyll compacting was observed. In the stem of $A$. philoxeroides exposed to $50 \mathrm{mg} \mathrm{L}^{-1} \mathrm{Cd}$, the nuclei of the cortex cells became elliptic, and at 25 and $50 \mathrm{mg} \mathrm{L}^{-1} \mathrm{Cd}$, the number of druses in the cells of the central leaf vein was reduced. Cd accumulation was higher in the roots, followed by the stem and leaves in A. philoxeroides. The net photosynthesis rate of $P$. ferrugineum was more affected by Cd than that of A. philoxeroides. There was no variation in photosystem II ( Fv/Fm) activity between the two species and the Cd treatments. A. philoxeroides was more cadmium-tolerant than $P$. ferrugineum, which indicates its capacity for use in phytoremediation programs.

Key words: Alternanthera philoxeroides, chlorophyll fluorescence, heavy metal, leaf gas exchange, phytoremediation, Polygonum ferrugineum

\section{Introdução}

O cádmio (Cd) é um elemento químico relativamente raro, não encontrado em estado puro na natureza, sendo utilizado em ligas, indústrias automotivas, pigmentos, estabilizantes para plásticos de polivinil, baterias e fertilizantes fosfatados (Malavolta 1994). No ambiente, tende a se concentrar nos solos e nos sedimentos de sistemas aquáticos, tornando-se disponível ao sistema radicular de plantas. Dessa maneira, o acúmulo de $\mathrm{Cd}$ nos tecidos de espécies vegetais aumenta o risco de transferência, por meio da cadeia alimentar, para seres humanos e animais (Vecchia et al. 2005).

Em concentrações elevadas os metais pesados, essenciais e não essenciais, podem levar a sintomas de toxicidade nos vegetais (Hall 2002). A exposição de plantas

\footnotetext{
1 Universidade Estadual de Santa Cruz, Departamento de Ciências Biológicas, Rodovia Ilhéus - Itabuna, km 16, $45662-000$ Salobrinho, Ilhéus, BA, Brasil

2 Autor para correspondência: delmira@uesc.br
} 
a quantidades tóxicas de $\mathrm{Cd}$ resulta em rápido declínio da capacidade de absorção e acúmulo deste elemento pelas raízes, principalmente em função da redução generalizada do metabolismo (Oliveira et al. 2001). Diversos estudos têm demonstrado que Cd causa diminuição da transpiração e da fotossíntese, aumento da taxa respiratória, clorose foliar, inibição do crescimento de raízes e da parte aérea e redução no acúmulo de matéria seca (Knecht et al. 1994; Schützendübel et al. 2001; Soltan \& Rashed 2003; Vecchia et al. 2005).

Segundo Hall (2002), os sintomas de toxicidade visíveis em concentrações excessivas de metais pesados podem ser atribuídos a uma extensa interação em níveis celulares e moleculares. O Cd interfere em muitas funções celulares, principalmente pela formação de complexos com grupos externos de compostos orgânicos, tais como as proteínas, resultando na inibição de atividades essenciais (Metwally et al. 2003). Além disso, pode provocar alterações nos sistemas antioxidantes, estimulando o acúmulo de peróxido de hidrogênio $\left(\mathrm{H}_{2} \mathrm{O}_{2}\right)$ e eventualmente morte celular (Schützendübel et al. 2001).

A caracterização anatômica constitui uma ferramenta que, associada com parâmetros morfo-fisiológicos, pode auxiliar a seleção de espécies para fitorremediação de ambientes contaminados por metais pesados, pois permite identificar mecanismos de tolerância por meio de alterações histológicas (Vecchia et al. 2005). Dentre estes mecanismos, os mais estudados são o acúmulo de Cd em células especializadas da epiderme, tricomas, e a co-cristalização de $\mathrm{Cd}$ com Ca formando cristais no interior do vacúolo (Salt et al. 1995; Mazen \& El Maghraby 1997; Lavid et al. 2001a; b).

A fitorremediação consiste em um conjunto de tecnologias que faz uso de processos, que ocorrem naturalmente, pelos quais as plantas e a flora microbiana em sua rizosfera degradam e seqüestram poluentes orgânicos e inorgânicos de solos e águas contaminadas (Pilon-Smits 2005). Tem alcançado popularidade em agências governamentais e indústrias que dispõem de orçamentos limitados, principalmente, pelos baixos custos, quando comparada aos outros métodos de remediação. Além disso, é um processo sustentável, ecológico e oferece a possibilidade de recuperação de elementos metálicos (Pilon-Smits 2005).

O rio Cachoeira, localizado na região Sul da Bahia, Brasil, tem sofrido intenso processo de degradação, causado, principalmente, pela descarga de esgotos urbanos não tratados em suas águas, pelo uso de fertilizantes e pesticidas em lavouras de cacau e presença de curtumes clandestinos em suas margens. Tal processo de degradação representa um risco à saúde da população ribeirinha, a qual utiliza o ecossistema do rio para pesca, como recurso alimentar para o gado, atividades domésticas e irrigação (Klumpp et al. 2002).

Investigações dos sedimentos e da água em diferentes pontos do rio Cachoeira, detectaram a ocorrência de metais pesados, dentre estes, o Cd que foi encontrado em concentrações traços (dados não publicados). A exposição ao $\mathrm{Cd}$ tem sido ligada a numerosos efeitos adversos a saúde humana, com mudanças patológicas distintas em uma variedade de tecidos e órgãos incluindo: o desenvolvimento ou progressão de complicações renais diabéticas, hipertensão, osteoporose, leucemia, infertilidade e câncer em vários órgãos como rins, pâncreas, pulmão, bexiga, mama e próstata (Satarug et al. 2003). Dessa forma, tem-se desenvolvido o estudo de métodos que possam vir a ser empregados na descontaminação de águas poluídas por este elemento metálico.

O presente trabalho teve como objetivo avaliar a capacidade fitorremediadora de Alternanthera philoxeroides e Polygonum ferrugineum, por meio da análise anatômica e do comportamento fotossintético, quando submetidas a diferentes concentrações de cádmio. A escolha destas espécies teve como critério à ocorrência natural às margens do rio Cachoeira sob impacto por contaminação com metais pesados, o que poderá facilitar o desenvolvimento de futuros projetos de controle da poluição com o emprego de métodos de fitorremediação.

\section{Material e métodos}

Material botânico - Polygonum ferrugineum Wedd. (Polygonaceae) é uma erva perene, aquática ou terrestre, ereta ou ascendente, fixa, cerca de $60-100 \mathrm{~cm}$ alt., ramificada na parte superior; caule lenhoso, oco, $2-3 \mathrm{~cm}$ diâm.; folhas alternas, oblongo-lanceoladas; flores róseas com máculas alvas. Espécie cosmopolita, no Brasil ocorre no Paraná, Goiás, Mato Grosso do Sul, Distrito Federal, Bahia, Ceará e Amazonas (Melo 2000). Muito utilizada na farmacopéia popular, geralmente ocorre infestando áreas inundadas como represas e lagos (Pott \& Pott 2000). Alternanthera philoxeroides (Mart.) Griseb. (Amaranthaceae) é uma erva perene, aquática ou terrestre, fixa, ereta ou ascendente, rizomatosa e estolonífera, pouco ramificada, glabra; caule cilíndrico, rosado, oco, 0,8-1,5 cm diâm.; folhas opostas, oblongas e elípticas; flores alvo-amareladas, organizadas em glomérulos terminais. Seu uso popular reside na utilização como forragem para gado e pequenos animais de áreas alagadas, como componente de ração para lagosta e alimento para abelhas (Pott \& Pott 2000). Nativa da parte meridional da América do Sul, também, é considerada 
planta daninha, pois infesta plantação de arroz inundada, canais de irrigação e drenagem, lagoas e represas (Lorenzi 2000). Em alguns países, tem sido utilizada para produção de biogás (Naqvi \& Rizvi 2000). Os espécimestestemunho das populações estudadas foram herborizados e encontram-se depositados no acervo do Herbário da Universidade Estadual de Santa Cruz (HUESC) (E.A. Rocha 732, 735, 1041, 1046). Os nomes dos autores das espécies estão abreviados de acordo com Brummitt \& Powel (1992).

Coleta e condições de cultivo - As espécies utilizadas nesse estudo foram coletadas ao longo do rio Cachoeira, numa área localizada próxima ao bairro Banco da Vitória, situado no município de Ilhéus, Bahia, Brasil, entre os meridianos $14^{\circ} 47^{\prime}-14^{\circ} 48^{\prime}$ de latitude Sul e $39^{\circ} 06^{\prime}$ $39^{\circ} 08^{\prime}$ de longitude Oeste. Após a coleta, as amostras das duas espécies foram transportadas em baldes plásticos, com as raízes imersas em água, para a casa de vegetação (radiação fotossinteticamente ativa $800 \pm 35 \mu \mathrm{mol} \mathrm{m} \mathrm{m}^{-2} \mathrm{~s}^{-1}$, fotoperíodo $12 \mathrm{~h}$, temperatura média de $23 \pm 1^{\circ} \mathrm{C}$ e umidade relativa média de $84 \pm 3$ ${ }^{\circ} \mathrm{C}$ ) e colocadas em bandejas plásticas (oito plantas/ bandeja), com capacidade de $30 \mathrm{~L}$, contendo solução nutritiva de $1 / 4$ de força iônica, preparada segundo Hoagland \& Arnon (1950), onde permaneceram por um período de adaptação de 30 dias. Posteriormente, foi procedida a troca da solução nutritiva, mantendose a mesma concentração, e a implementação dos tratamentos com 25 e $50 \mathrm{mg} \mathrm{L}^{-1} \mathrm{Cd}$ na forma $\mathrm{CdCl}_{2}$, juntamente com o controle (sem Cd), num total de três repetições (bandeja) por tratamento. As soluções foram monitoradas quanto ao $\mathrm{pH}$ e ajustadas para 5,8 utilizando-se $\mathrm{NaOH}$ ou $\mathrm{HCl}$. O nível diário da solução nutritiva foi mantido pela reposição diária do volume com água deionizada, que permaneceu sob aeração constante.

Análise anatômica - Sete dias após a aplicação dos tratamentos (DAAT) foram realizadas coletas dos órgãos vegetativos de três diferentes plantas, selecionadas aleatoriamente por tratamento, para as análises anatômicas. Amostras de ápices e região mediana de raízes, de nós e entrenós caulinares e da porção mediana das folhas foram fixadas em FAA 70. O material foi desidratado em série etanólica, incluído em historresina (Leica), conforme instrução do fabricante, seccionado ao micrótomo rotativo e submetido ao processo de coloração com azul de toluidina a 1\% (O’Brien et al. 1990). Realizaram-se testes histoquímicos, em secções feitas à mão livre com lâmina de barbear, utilizando lugol para detecção de amido (Johansen 1940), floroglucina acidificada para lignina (Jensen 1962), cloreto férrico (Johansen 1940), para compostos fenólicos e sudan III para suberina (Jensen 1962). A quantificação dos tricomas, em secção paradérmica da folha, e dos idioblastos contendo compostos fenólicos, em secção transversal do caule, foi realizada através de câmara clara acoplada ao microscópio (Poole \& Kürschner 1999). Para cada tratamento foram analisadas três plantas. A mensuração do espaço lacunar do aerênquima foi realizada de acordo com a metodologia de Sundberg (1992). Os resultados foram documentados em fotomicroscópio Olympus 50 com filme Fuji Asa 400.

Medições de trocas gasosas foliares e da emissão de fluorescência da clorofila - Devido ao baixo índice de sobrevivência de uma das espécies selecionadas para este estudo até 15 DAAT (Polygonum ferrugineum), as medições de trocas gasosas e da emissão de fluorescência da clorofila na folha foram realizadas apenas aos sete DAAT. Para essas análises selecionou-se a segunda ou terceira folha madura (três plantas por bandeja e uma folha por planta, totalizando nove medições por tratamento) a partir do ápice caulinar, no horário entre 8 e $12 \mathrm{~h}$, utilizando um medidor portátil de trocas gasosas LI-6400 (Li-Cor Inc., Nebraska, USA), equipado com uma fonte de luz artificial 6400 - 02B RedBlue \# SI 925. A radiação fotossinteticamente ativa (RFA) foi fixada em $800 \mu \mathrm{mol} \mathrm{m} \mathrm{m}^{-2} \mathrm{~s}^{-1}$ acima da irrandiância de saturação de luz das espécies vegetais avaliadas, com exceção de RFA, não houve controle das variáveis microclimáticas no interios da câmara do aparelho durante a realização das medições. Foram estimados as taxas de fotossíntese líquida (A), a condutância estomática ao vapor de água (gs) e o défice de pressão de vapor de água entre a folha e o ar (DPV). As medições da emissão de fluorescência da clorofila foram efetuadas na mesma folha utilizada para as medições de trocas gasosas com um fluorômetro portátil FMS-2 (Hansatech Instruments Ltda, UK). Antes das medições serem realizadas colocou-se um clipe na região mediana da folha, permitindo-se que esta região permanecesse no escuro por um período mínimo de 20 min., para que todos os centros de reações adquirissem a condição de oxidados. Assim, após as medições, foi obtida a razão entre a fluorescência variável $(\mathrm{Fv})$ e a máxima (Fm), (Fv/Fm).

Determinação do teor de cádmio - Ao final do experimento, 15 DAAT, coletou-se três plantas por unidade experimental (um total de nove plantas diferentes por tratamento) da espécie A. philoxeroides dos diferentes tratamentos, juntamente com o controle, que, em seguida, foram lavadas em água deionizada e separadas em raiz, caule e folha. As amostras dos órgãos vegetativos foram acondicionadas, separadamente, em sacos de papel e colocadas imediatamente em estufa de ventilação forçada de ar a $75{ }^{\circ} \mathrm{C}$, até massa constante, 
para obtenção da biomassa seca. Após a secagem, os diferentes órgãos foram moídos em moinho tipo Wiley, seguido da análise do material vegetal por Inductively Coupled Plasma Mass Spectrometry (ICP-MS). Entretanto, não foi possível realizar essa análise para P. ferrugineum devido ao baixo índice de sobrevivência desta espécie aos 15 DAAT.

Análise estatística - O delineamento experimental adotado foi inteiramente casualizado, com três tratamentos, referentes às concentrações de $\mathrm{Cd}$ e controle, três repetições e oito plantas por unidade experimental (bandeja) totalizando 24 plantas por tratamento. Os resultados obtidos foram submetidos à análise de variância, seguido do teste de Tukey em nível de $1 \%$ e $5 \%$ de probabilidade.

\section{Resultados}

Respostas anatômicas - A raiz de P. ferrugineum apresenta epiderme unisseriada, região cortical ampla constituída de aerênquima, delimitada internamente pela endoderme, seguida ao centro pelo cilindro vascular (Fig. 1). Nesta espécie, quando submetida a concentração de $25 \mathrm{mg} \mathrm{L}^{-1} \mathrm{Cd}$, observou-se a necrose das células dos tecidos mais externos da raiz: epiderme e aerênquima (Fig. 2). No tratamento $50 \mathrm{mg} \mathrm{L}^{-1} \mathrm{Cd}$ foi verificado o aumento das lacunas do aerênquima (Fig. 3), embora estatisticamente não significante (Tab.1), assumindo este tecido um padrão morfológico distinto do verificado no controle (Fig. 1).

O caule de $P$. ferrugineum em crescimento secundário caracteriza-se por apresentar epiderme unisseriada, seguida de uma faixa contínua com quatro a cinco camadas de colênquima, sendo duas a três camadas de colênquima lamelar, seguidas de uma a duas camadas de colênquima lacunar (Fig. 4). Ainda internamente a epiderme, a primeira camada do colênquima dá origem a instalação do felogênio (Fig. 4). Embora não quantificado, observou-se visualmente o aumento do número de camadas do colênquima lamelar e lacunar para a concentração $50 \mathrm{mg} \mathrm{L}^{-1} \mathrm{Cd}$ (Fig. 5), em comparação ao controle. Neste órgão, em crescimento secundário, o cilindro vascular circunda uma ampla medula, na qual os testes histoquímicos revelaram o aumento estatisticamente significante de idioblastos contendo compostos fenólicos (Tab. 2), assim como na endoderme dos dois tratamentos, quando comparados ao controle (Fig. 6-8).

A folha de $P$. ferrugineum é caracterizada por apresentar um mesofilo dorsiventral, constituído por cerca de duas camadas de parênquima paliçádico e duas de parênquima esponjoso, presença de estômatos e tricomas glandulares nas duas faces da folha (Fig. 9-11).
Após exposição a $50 \mathrm{mg} \mathrm{L}^{-1} \mathrm{Cd}$, observou-se neste órgão a compactação do mesofilo (Fig. 11), contudo, sem alterar significativamente a espessura do mesofilo quando comparado ao controle e ao tratamento $25 \mathrm{mg} \mathrm{L}^{-1} \mathrm{Cd}$ (Tab. 1). Além disso, foi observado o aumento, estatisticamente significante, de tricomas glandulares nas duas faces da epiderme no tratamento $50 \mathrm{mg} \mathrm{L}^{-1} \mathrm{Cd}$, quando comparado ao controle (Tab. 2). Nas folhas tratadas com 25 e $50 \mathrm{mg} \mathrm{L}^{-1} \mathrm{Cd}$, embora estatisticamente não significante, observou-se o aumento das lacunas do aerênquima na região da nervura central (Tab.1), resultando num padrão morfológico distinto quando comparado ao tratamento controle (Fig. 12-14). Nos tricomas foi evidenciado ainda, através de teste histoquímico, o acúmulo de compostos fenólicos (Fig. 15).

Em A. philoxeroides não foram observadas alterações anatômicas nos órgãos analisados neste estudo. As principais alterações estruturais foram restritas à morfologia celular, com o núcleo apresentando conspícuas modificações. Os elementos traqueais localizados na região da nervura central da folha do tratamento controle, caracterizaram-se pela abundância de drusas, cuja ocorrência tornou-se escassa na medida em que as dose de $\mathrm{Cd}$ foi aumentada entre os tratamentos (Fig. 16-21). No ápice radicular das plantas submetidas à concentração de $25 \mathrm{mg} \mathrm{L}^{-1} \mathrm{Cd}$, foi verificado, nos tecidos situados na região cortical, que o núcleo com formato arredondado e posição centralizada nas plantas controle (Fig. 22), mostrou-se fragmentado e deslocado para a periferia celular (Fig. 23), ao passo que na mesma região da raiz das plantas cultivadas com $50 \mathrm{mg} \mathrm{L}^{-1} \mathrm{Cd}$ sua visualização tornou-se imprecisa (Fig. 24). Aspecto semelhante ocorreu nas células do parênquima cortical do caule das plantas submetidas a 25 e a $50 \mathrm{mg} \mathrm{L}^{-1} \mathrm{Cd}$. Nesse caso, o núcleo apresentou-se modificado, assumindo o formato elíptico quando comparado ao controle (Fig. 25-27).

Acúmulo de Cd e efeitos sobre a fotossíntese Enquanto gs diminuiu significativamente em relação ao controle nas duas espécies analisadas, apenas em P. ferrugineum houve um decréscimo em A para a concentração de $50 \mathrm{mg} \mathrm{L}^{-1} \mathrm{Cd}$ (Tab. 3). Não foram observadas diferenças significativas entre os tratamentos para Fv/Fm (Tab. 3).

Em A. philoxeroides o Cd acumulou-se significativamente no sistema radicular, no caule e na folha, em ordem decrescente (Tab. 3). Não houve diferença significativa nos teores de $\mathrm{Cd}$, nos diferentes órgãos desta espécie, entre os tratamentos com o metal (Tab. 4). 


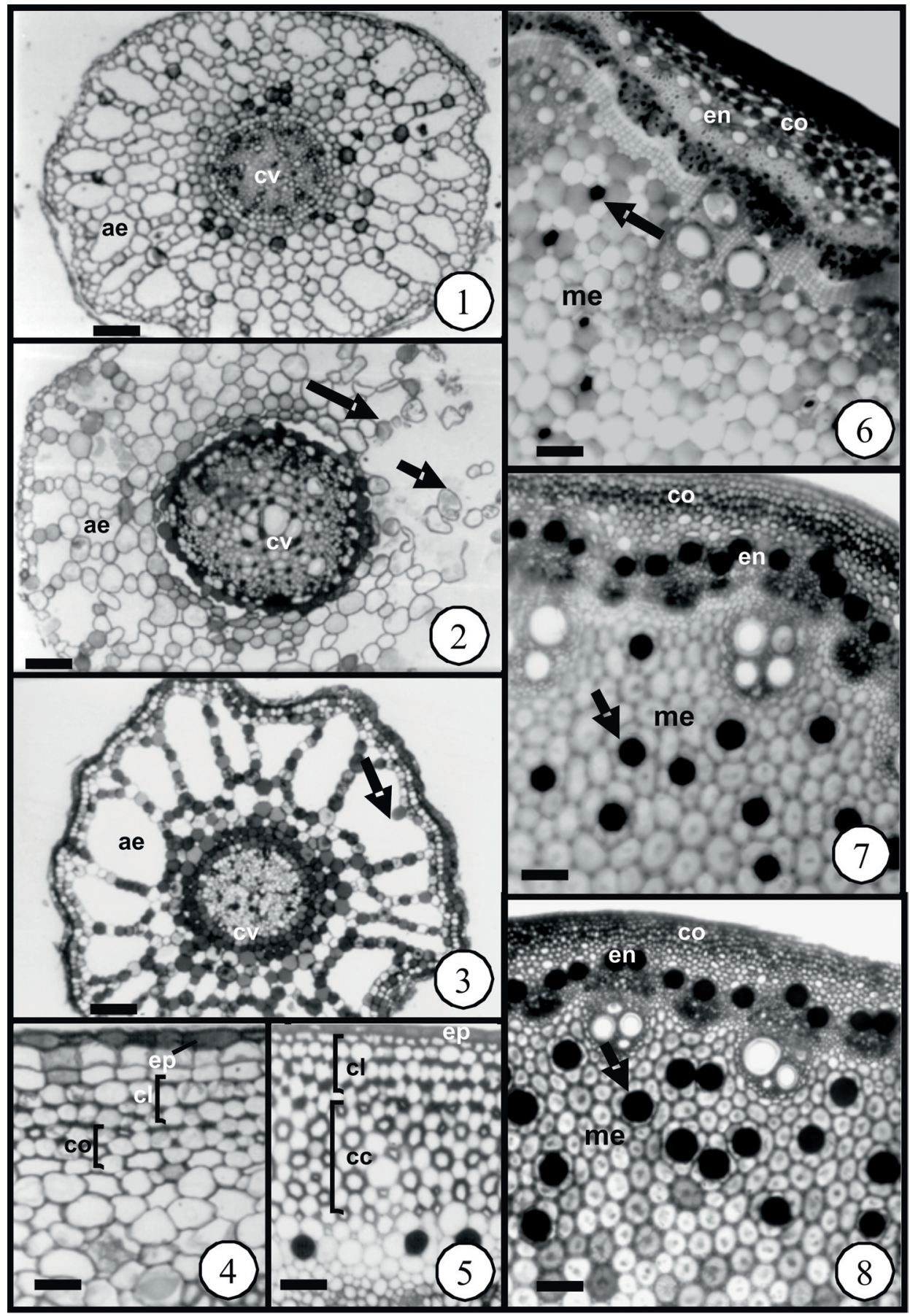

Figuras 1-8. Polygonum ferrugineum Wedd. após aplicação dos tratamentos com Cd. 1. Secção transversal da raiz do tratamento controle. 2. Secção transversal da raiz da concentração $25 \mathrm{mg} \mathrm{L}^{-1}$ evidenciando necrose do tecido cortical da raiz (setas). 3. Secção transversal da raiz na concentração $50 \mathrm{mg} \mathrm{L}^{-1}$ destacando o aumento das lacunas do aerênquima (seta). 4. Região cortical do caule do tratamento controle, em secção transversal, evidenciando a presença de colênquima lamelar e lacunar. 5. Detalhe do córtex do caule na concentração 50 mg $\mathrm{L}^{-1}$, evidenciando o aumento das camadas de colênquima lamelar e lacunar. 6. Secção transversal do caule controle submetida ao teste histoquímico com cloreto férrico: seta indica idioblasto com acúmulo de composto fenólico. 7. Teste histoquímico com cloreto férrico do caule do tratamento $25 \mathrm{mg} \mathrm{L}^{-1}$ destacando o aumento no acúmulo de compostos fenólicos na endoderme e em idioblastos situados na medula (seta). 8. Teste histoquímico com cloreto férrico do caule para o tratamento $50 \mathrm{mg} \mathrm{L}^{-1}$, evidenciando o aumento de idioblastos com conteúdo fenólico (seta). Abreviaturas: epiderme (ep); colênquima (co), colênquima lamelar (cl), colênquima lacunar (cc); aerênquima (ae); endoderme (en); medula (me); cilindro vascular (cv). Barras $=60 \mu \mathrm{m}(1-3,6-8) ; 30 \mu \mathrm{m}(4-5)$. 
Tabela 1. Valores médios ( \pm dp) da espessura do mesofilo e do volume do aerênquima do córtex da raiz e da nervura central foliar de Polygonum ferrugineum Wedd. submetida a diferentes concentrações de cádmio em solução nutritiva, $(\mathrm{n}=3)$.

\begin{tabular}{cccc}
\hline $\mathrm{Cd}\left(\mathrm{mg} \mathrm{L}^{-1}\right)$ & $\begin{array}{c}\text { Espessura mesofilo } \\
(\mu \mathrm{m})\end{array}$ & $\begin{array}{c}\text { Aerênquima } \\
(\text { Raiz) }\end{array}$ & $\begin{array}{c}\text { Aerênquima } \\
\text { (Nervura central) }\end{array}$ \\
\hline 0 & $15,72 \pm 0,91 \mathrm{~A}$ & $0,09 \pm 0,007 \mathrm{~A}$ & $0,30 \pm 0,010 \mathrm{~A}$ \\
25 & $17,42 \pm 0,95 \mathrm{~A}$ & $0,14 \pm 0,013 \mathrm{~A}$ & $0,29 \pm 0,029 \mathrm{~A}$ \\
50 & $13,88 \pm 0,24 \mathrm{~A}$ & $0,16 \pm 0,052 \mathrm{~A}$ & $0,40 \pm 0,006 \mathrm{~A}$ \\
\hline
\end{tabular}

Para cada variável as mesmas letras maiúsculas nas colunas não diferem estatisticamente entre si pelo teste de Tukey $(\mathrm{p}<0,01)$.

Tabela 2. Valores médios $( \pm \mathrm{dp})$ da densidade de tricomas e de idioblastos fenólicos de Polygonum ferrugineum Wedd. submetida a diferentes concentrações de cádmio em solução nutritiva, $(n=3)$.

\begin{tabular}{cccc}
\hline $\mathrm{d}\left(\mathrm{mg} \mathrm{L}^{-1}\right)$ & $\begin{array}{c}\text { Tricoma face abaxial } \\
\text { (Folha) }\end{array}$ & $\begin{array}{c}\text { Tricoma face adaxial } \\
\text { (Folha) }\end{array}$ & $\begin{array}{c}\text { Idioblastos } \\
\text { (Caule) }\end{array}$ \\
\hline 0 & $7,67 \pm 0,53 \mathrm{~A}$ & $8,2 \pm 0,29 \mathrm{~A}$ & $3,25 \pm 0,47 \mathrm{~A}$ \\
25 & $8,1 \pm 0,51 \mathrm{~A}$ & $10,26 \pm 0,13 \mathrm{~A}$ & $11,62 \pm 0,77 \mathrm{~B}$ \\
50 & $16,07 \pm 0,32 \mathrm{~B}$ & $16,23 \pm 0,95 \mathrm{~B}$ & $16,45 \pm 0,87 \mathrm{C}$ \\
\hline
\end{tabular}

Para cada variável as mesmas letras maiúsculas nas colunas não diferem estatisticamente entre si pelo teste de Tukey $(\mathrm{p}<0,01)$.

\section{Discussão}

Em plantas aquáticas, o aerênquima desenvolve-se principalmente por desintegração de células, seguindo uma sequência de fatos: a deficiência de oxigênio promove a produção de etileno pelo estimulo anaeróbico, o qual causa um aumento na atividade da celulase, que conduz a desintegração de células e o desenvolvimento de aerênquima (Fahn 1982). Neste caso, o aerênquima funciona como uma estratégia alternativa para a obtenção de $\mathrm{O}_{2}$ (Drew et al. 2000). O mesmo fato pode ser observado na presença de $\mathrm{Cd}$, pois este elemento metálico estimula a produção de etileno em espécies vegetais (Chen \& Kao 1995; Toppi et al. 1998). Embora neste estudo não tenha sido avaliado a concentração de etileno nos diferentes tratamentos, acredita-se que as modificações observadas nas lacunas do aerênquima das raízes e da nervura central foliar de $P$. ferrugineum podem estar relacionadas à alteração nas concentrações desse hormônio. Desta forma, ainda que o ambiente externo esteja hipóxico, ou mesmo anóxico, internamente a raiz utiliza-se desta estratégia para manter a planta aerada (Dantas et al. 2001).

O aumento da produção de compostos fenólicos verificado no caule de $P$. ferrugineum submetido a 25 e a $50 \mathrm{mg} \mathrm{L}^{-1} \mathrm{Cd}$, também foi verificado por Schützendübel et al. (2001) em raízes de Pinus sylvestris L., imediatamente após a exposição dos ápices de raízes ao $\mathrm{Cd}$, sugerindo que a produção de tais substâncias pode estar envolvida na proteção da planta contra o estresse oxidativo. Acredita-se que a produção destes compostos esteja relacionada ao acúmulo de metal, pois de acordo com Lavid et al. (2001b) polifenóis, especialmente taninos, são bem conhecidos pela capacidade de quelar metais pesados. Estes autores constataram ainda que tais compostos estão envolvidos no acúmulo de $\mathrm{Cd}$, pois encontraram depósitos de fenóis em glândulas da epiderme do pecíolo e do rizoma de Nymphaea L. tratadas com este metal. Vecchia et al. (2005) também relacionaram a presença de polifenóis na parede celular de Elodea canadenses Michx. à sua capacidade de quelar metais pesados.

Neste estudo, acredita-se que os tricomas glandulares em $P$. ferrugineum podem estar relacionados à função de acumulação de $\mathrm{Cd}$ em decorrência do aumento, em número, destas estruturas epidérmicas na superfície foliar das plantas tratadas com este metal e pelo fato de acumularem compostos fenólicos que podem atuar no sequestro de $\mathrm{Cd}$. A função dos tricomas glandulares na tolerância a metais pesados é amplamente discutida na literatura, sendo descritos como células epidérmicas que podem acumular metais pesados ou secretá-los, visto que estas estruturas fazem parte do tecido mais externo da folha (Salt et al. 1995; MacFarlane \& Burchett 1999; Küpper et al. 2000; Psaras et al. 2000; Lavid et al. 2001a).

O Cd ocasionou a compactação do mesofilo de P. ferrugineum. A diminuição dos espaços intercelulares em folhas de Brassica juncea (L.) Czern., foi observada por Sridhar et al. (2005), após exposição ao Zn, enquanto 


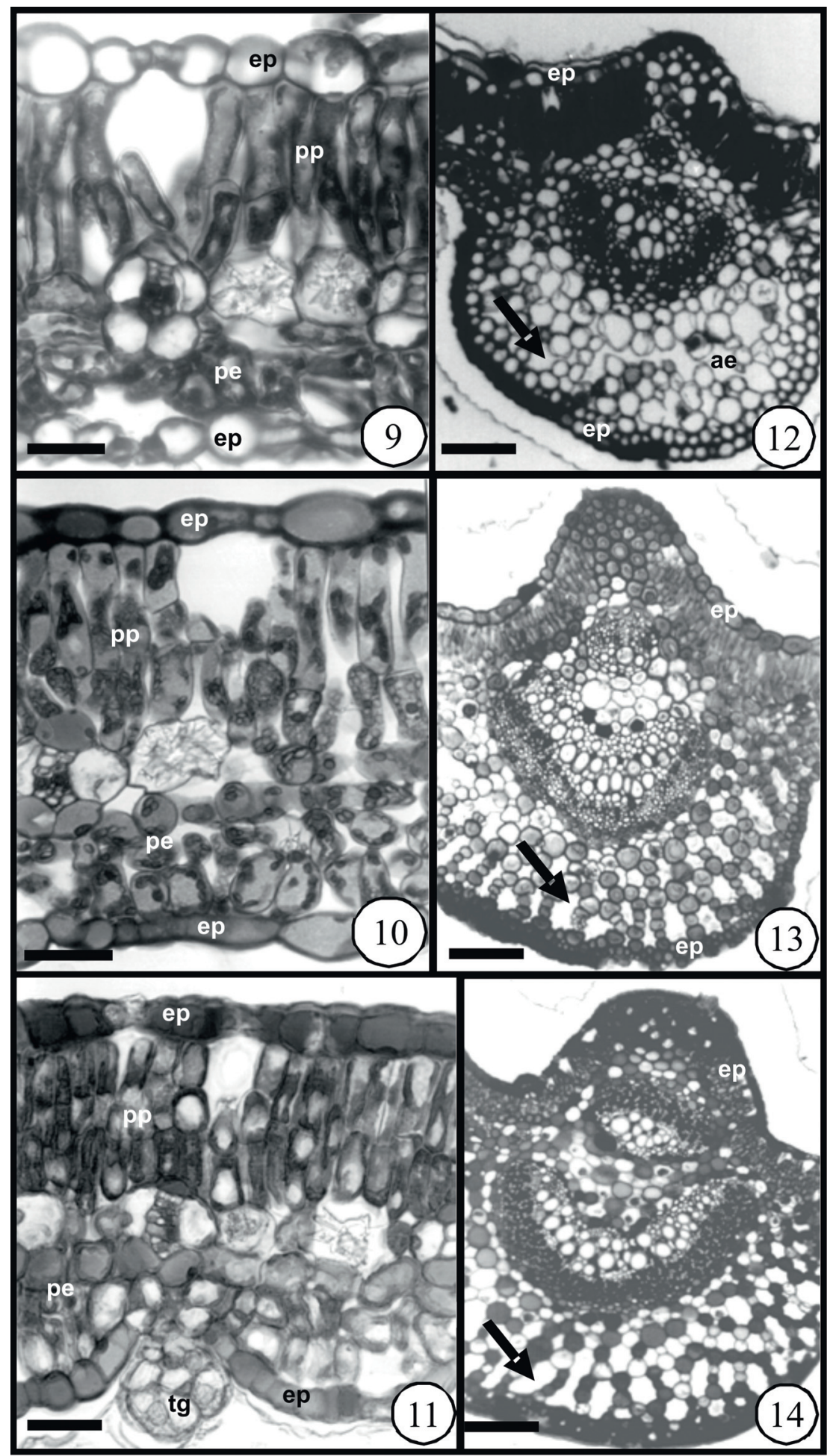

Figuras 9-14. Secção transversal da folha de Polygonum ferrugineum Wedd. tratada com Cd. 9. Detalhe do mesofilo dorsiventral do tratamento controle. 10. Detalhe do mesofilo da concentração $25 \mathrm{mg} \mathrm{L}^{-1}$. 11. Detalhe do mesofilo da concentração $50 \mathrm{mg} \mathrm{L}^{-1}$ evidenciando tricoma glandular (tg). 12. Detalhe da nervura central do tratamento controle. 13. Detalhe da nervura central da concentração $25 \mathrm{mg} \mathrm{L}^{-1}$. 14. Detalhe da nervura central da concentração $50 \mathrm{mg} \mathrm{L}^{-1}$. Setas nas figuras 12-14 destacam lacunas do aerênquima. Abreviaturas: epiderme (ep); tricoma glandular (tg); parênquima paliçadico (pp); parênquima esponjoso (pe); aerênquima (ae). Barras $=30 \mu \mathrm{m}(9-11)$, 170 $\mu \mathrm{m}(12-14)$. 
que o tratamento com $\mathrm{Cd}$ não causou mudanças na morfologia do mesofilo. Já em E. canadenses as células do mesofilo apresentaram aumento de volume após exposição ao $\mathrm{Cd}$, o que levou a um declínio no número de células por área (Vecchia et al. 2005).
Cristais, em geral, são mais freqüentes em plantas sob determinadas condições de estresse, sendo considerados como produtos finais do metabolismo celular, podem funcionar como meio de remoção do excesso de oxalato de cálcio, acumulando em

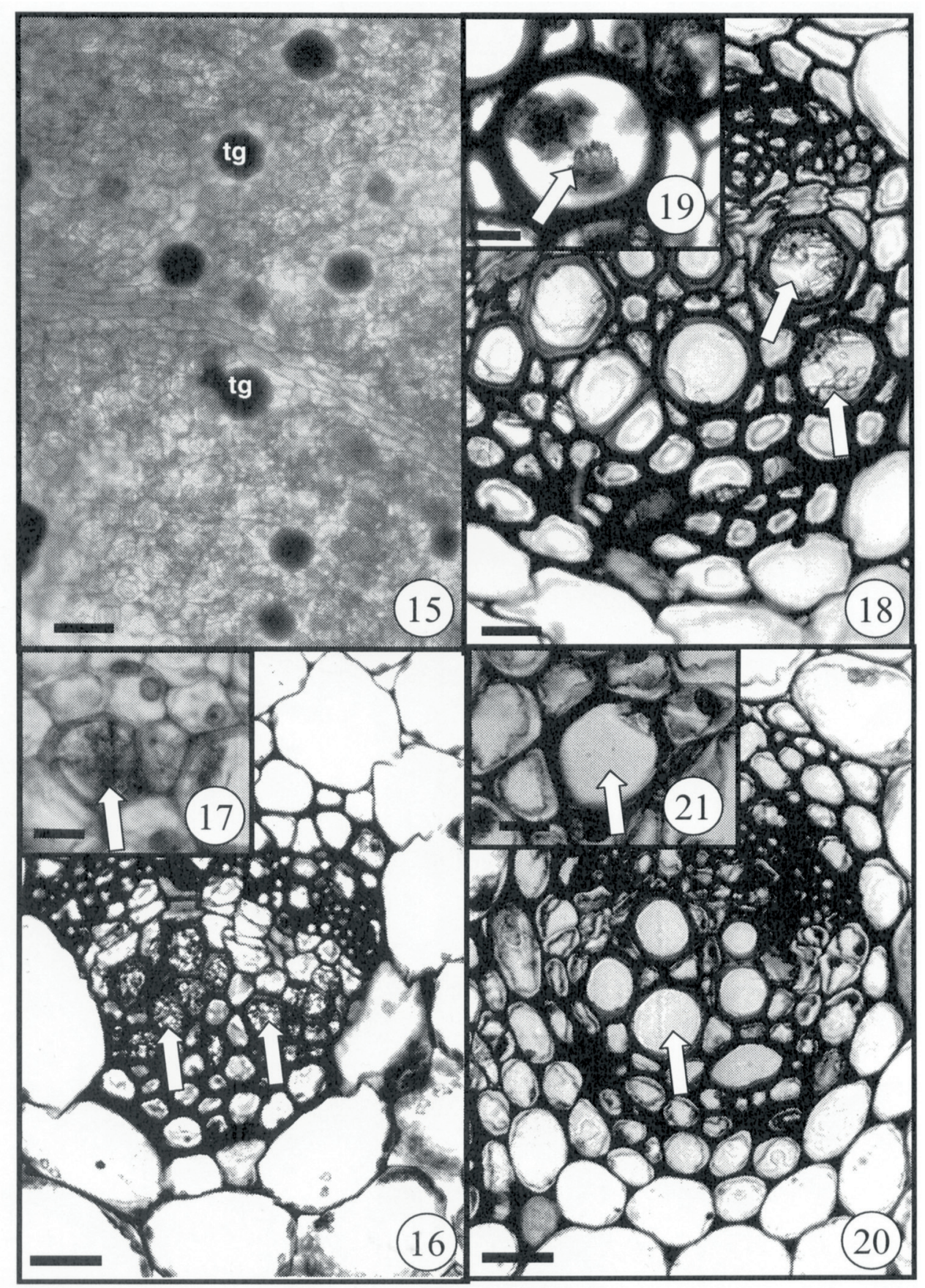

Figuras 15-20. Aspectos anatômicos da folha tratada com Cd. 15. Polygonum ferrugineum Wedd.: detalhe da face adaxial, em vista frontal, evidenciando tricomas glandulares com resultado positivo para compostos fenólicos. 16-17. Secção transversal da nervura central do tratamento controle de Alternanthera philoxeroides (Mart.) Griseb. destacando a presença de drusas nos elementos traqueais (setas). 17. Detalhe da drusa no interior do elemento traqueal (seta); 18-19. Nervura central de A. philoxeroides tratada na concentração 25 mg $\mathrm{L}^{-1}$ evidenciando a redução de drusas nos elementos traqueais. 18. Detalhe da drusa no interior do elemento traqueal (seta); 20-21. Nervura central de A. philoxeroides tratada na concentração $50 \mathrm{mg} \mathrm{L}^{-1}$ mostrando a ausência das drusas nos elementos traqueais (setas). 20. Detalhe do elemento traqueal sem drusa. Abreviatura: tricoma glandular (tg). Barras $=30 \mu \mathrm{m}(15) ; 20 \mu \mathrm{m}(16,18,20), 10 \mu \mathrm{m}(17,19,21)$. 
quantidades tóxicas no interior da célula (Franceschi \& Horner 1980). Em condições de deficiência de Ca pode haver a reabsorção dos cristais, indicando que há uma estocagem temporária de $\mathrm{Ca}$ no idioblasto (Franceschi \& Horner 1980). O Cd, juntamente com o Ca, pode se acumular no vacúolo formando cristais, como observado por Lavid et al. (2001a) em Nymphaea. Da mesma forma, Mazen \& El Maghraby (1997) verificaram que durante a exposição de Eichhornia crassipes (Mart) Solms aos metais $\mathrm{Cd}, \mathrm{Pb}, \mathrm{Sr}$ ocorreu o aumento

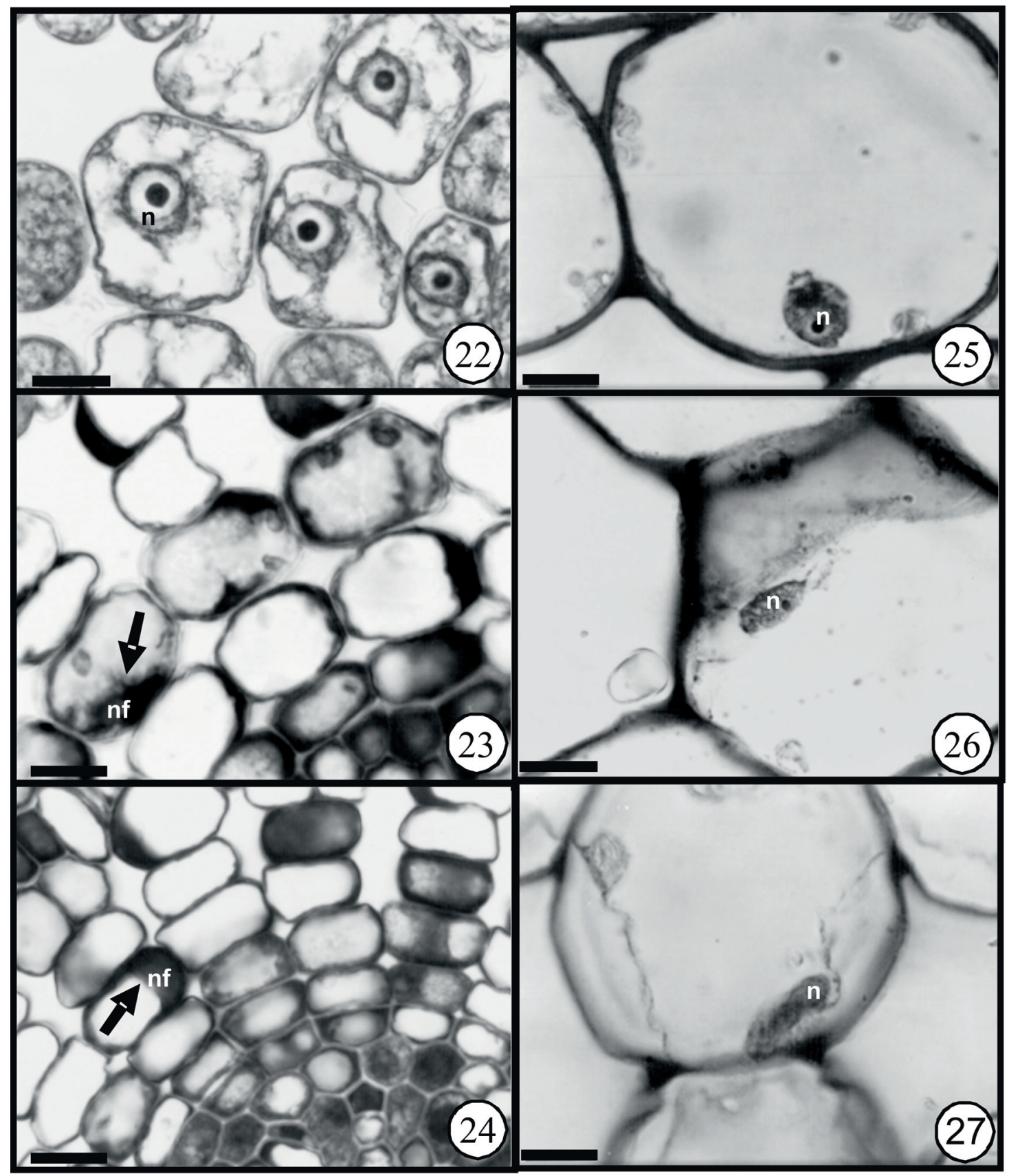

Figuras 22-27. Secção transversal da raiz (ápice radicular) e do caule de Alternanthera philoxeroides (Mart.) Griseb. após tratamento com Cd. 22. Aspecto da região cortical da raiz do tratamento controle evidenciando a morfologia do núcleo celular. 23. Detalhe da região cortical da raiz na concentração $25 \mathrm{mg} \mathrm{L}^{-1}$ mostrando fragmentos do núcleo localizados na periferia da célula. 24. Detalhe da região cortical da raiz na concentração $50 \mathrm{mg} \mathrm{L}^{-1}$ indicando fragmentos do núcleo. 25. Caule do tratamento controle evidenciando a morfologia do núcleo celular da região do córtex. 26. Caule, detalhe da célula cortical na concentração $25 \mathrm{mg} \mathrm{L}^{-1}$ evidenciando núcleo gradualmente deformado. 27. Caule, detalhe da célula cortical na concentração $50 \mathrm{mg} \mathrm{L}^{-1}$ mostrando núcleo com formato elíptico. Setas na figura 23 e 24 indicam fragmentos do núcleo. Abreviaturas: núcleo (n), fragmentos de núcleo (nf). Barras $=10 \mu \mathrm{m}$. 
Tabela 3. Valores médios $( \pm \mathrm{dp})$ da razão fluorescência variável e máxima $(\mathrm{Fv} / \mathrm{Fm})$, da condutância estomática $\left(\mathrm{gs}, \mathrm{mol} \mathrm{H}_{2} \mathrm{O} \mathrm{m}^{-2} \mathrm{~s}^{-1}\right)$ e da taxa fotossintética líquida (A, $\mu \mathrm{mol} \mathrm{CO}_{2} \mathrm{~m}^{-2} \mathrm{~s}^{-1}$ ) em duas macrófitas aquáticas aos sete dias após aplicação de diferentes concentrações de cádmio, $(\mathrm{n}=9)$.

\begin{tabular}{lcccc}
\hline Espécies & $\mathrm{Cd}\left(\mathrm{mg} \mathrm{L}^{-1}\right)$ & Fv/Fm & gs & A \\
\hline Polygonum ferrugineum & 0 & $0,87 \pm 0,02 \mathrm{~A}$ & $1,16 \pm 0,06 \mathrm{~A}$ & $24,07 \pm 1,22 \mathrm{~A}$ \\
& 25 & $0,87 \pm 0,02 \mathrm{~A}$ & $0,35 \pm 0,13 \mathrm{~B}$ & $16,56 \pm 3,69 \mathrm{~A}$ \\
Alternanthera philoxeroides & 50 & $0,87 \pm 0,01 \mathrm{~A}$ & $0,05 \pm 0,01 \mathrm{~B}$ & $4,33 \pm 1,52 \mathrm{~B}$ \\
& 0 & $0,82 \pm 0,002 \mathrm{~A}$ & $1,33 \pm 0,10 \mathrm{~A}$ & $23,40 \pm 1,36 \mathrm{~A}$ \\
& 25 & $0,77 \pm 0,002 \mathrm{~A}$ & $0,46 \pm 0,10 \mathrm{~B}$ & $17,17 \pm 1,66 \mathrm{~A}$ \\
& 50 & $0,77 \pm 0,009 \mathrm{~A}$ & $0,61 \pm 0,26 \mathrm{~B}$ & $17,78 \pm 1,60 \mathrm{~A}$ \\
\hline
\end{tabular}

Para cada espécie médias seguidas de mesma letra nas colunas não diferem entre si pelo teste de Tukey $(\mathrm{p}<0,05)$.

Tabela 4. Teores médios ( \pm dp) de cádmio (Cd) nos diferentes órgãos de Alternanthera philoxeroides (Mart.) Griseb. cultivada em concentrações crescentes de Cd em solução nutritiva, $(n=9)$.

\begin{tabular}{cccc}
\hline \multirow{2}{*}{ Cd $\left(\mathrm{mg} \mathrm{L}^{-1}\right)$} & \multicolumn{3}{c}{ Cd (mg kg $\mathrm{miomassa} \mathrm{seca})^{-1}$} \\
\cline { 2 - 4 } & Raiz & Caule & Folha \\
\hline 0 & $0,0 \mathrm{Aa}$ & $0,0 \mathrm{Aa}$ & $0,0 \mathrm{Aa}$ \\
25 & $18,8 \pm 1,1 \mathrm{Ba}$ & $4,0 \pm 0,4 \mathrm{Bb}$ & $0,36 \pm 0,03 \mathrm{Bc}$ \\
50 & $20,2 \pm 0,5 \mathrm{Ba}$ & $5,7 \pm 0,04 \mathrm{Bb}$ & $0,40 \pm 0,01 \mathrm{Bc}$ \\
\hline
\end{tabular}

As mesmas letras maiúsculas entre linhas e minúsculas entre colunas não diferem estatisticamente entre si pelo teste de Tukey $(\mathrm{p}<0,05)$.

progressivo da formação de cristais de oxalato de cálcio (ráfides). Em A. philoxeroides, entretanto, o que se observou foi um progressivo processo de reabsorção dos cristais formados no interior das células do xilema, situadas na nervura foliar, proporcional ao aumento da concentração de $\mathrm{Cd}$, o que se acredita estar relacionado ao declínio no transporte de Ca para a parte aérea, uma vez que, segundo Soares et al. (2005) o Cd interfere na absorção e na translocação deste macronutriente.

Sintomas semelhantes aos de morte celular programada, como a deformação e fragmentação de núcleos, verificados na raiz e no caule de A. philoxeroides, podem ser desencadeados com a elevação das concentrações de $\mathrm{H}_{2} \mathrm{O}_{2}$, o que ocorre, segundo Schützendübel et al. (2001), em virtude da interferência do Cd nos sistemas antioxidativos, atuando como inibidor simultâneo dos sistemas envolvidos na remoção de $\mathrm{H}_{2} \mathrm{O}_{2}$. Raízes de P. sylvestris expostas ao $\mathrm{Cd}$ demonstraram significante acúmulo de $\mathrm{H}_{2} \mathrm{O}_{2}$, após 24 h, o que resultou em morte celular (Schützendübel et al. 2001). Deformação do núcleo celular já foi verificada em folhas de A. philoxeroides submetidas à poluição por $\mathrm{Cd}$ (Zhou et al. 2003). Considerando-se que o Cd provoca o acúmulo de $\mathrm{H}_{2} \mathrm{O}_{2}$, as alterações morfológicas do núcleo verificadas neste estudo, podem estar relacionadas a este composto, como sugerem estudos realizados com células de Nicotiana tabacum L. BY2, cultivadas em suspensão após tratamento com $\mathrm{H}_{2} \mathrm{O}_{2}$, onde foi evidenciado núcleo com perda da arquitetura, exibindo forma de cordão ou estendido, sintomas característicos de células em processo de apoptose (Houot et al. 2001).

As raízes, possivelmente por constituírem a parte da planta que está diretamente em contato com o metal pesado, geralmente, apresentam os teores mais elevados de Cd (Oliveira et al. 2001). Em A. philoxeroides os valores médios dos teores de $\mathrm{Cd}$ indicaram maior acúmulo no sistema radicular do que na parte aérea, semelhante ao verificado por Oliveira et al. (2001), ao avaliarem a absorção e o acúmulo de $\mathrm{Cd}$ em E. crassipes e Salvinia auriculata Aubl., constatando o maior acúmulo de Cd nas raízes. Segundo Grant et al. (1998), o Cd pode se ligar às cargas negativas das paredes celulares da raiz e, posteriormente, ser transferido ou translocado para a parte aérea. Adicionalmente, admite-se que parte do $\mathrm{Cd}$ absorvido é complexado na forma de fitoquelatinas, porém a translocação deste metal através do xilema parece ser independente da produção de fitoquelatinas nas raízes, assim, não representam função direta no transporte de Cd para a parte aérea (Salt et al. 1995). Além disso, Dixit et al. (2001) ressaltam que o baixo acúmulo de Cd nas folhas pode ser uma estratégia para proteger as funções fotossintéticas do estresse oxidativo induzido por este metal.

Em A. philoxeroides a diminuição de gs deveu-se a um aumento de DPV evidenciado durante as medições de trocas. Em P. ferrugineum o decréscimo de A em resposta ao $\mathrm{Cd}$ foi acompanhado, também, por uma diminuição em gs, fato este que pode ter interferido no metabolismo desta espécie, provocando a sua morte após 15 dias de tratamento com o metal. De acordo com Mendelssohn et al. (2001) a atividade fotossintética decresce significativamente com o aumento da concentração de $\mathrm{Cd}$, sendo considerada como um indicador sensível do estresse ocasionado por este metal. Chugh \& Sawhney (1999) em estudos realizados com Pisum sativum L. evidenciaram que o $\mathrm{Cd}$ exerceu um efeito deletério sobre as enzimas fotossintéticas e A 
diminuiu progressivamente com aumento da concentração deste metal.

Observou-se que a razão Fv/Fm não foi afetada significativamente nas duas espécies analisadas, portanto o Cd não exerceu efeito sobre a fase fotoquímica da fotossíntese nestas espécies. Resultados similares foram encontrados por Medenlssohn et al. (2001) em estudos realizados com Thypha domingesis Pers. e Spartina alterniflora Loisel. Estes últimos autores concluíram ainda que, a razão Fv/Fm é menos sensível ao estresse ocasionado por $\mathrm{Cd}$, quando comparado com A, $\log$ o não constitui um bom indicador fisiológico para a avaliação do estresse induzido por $\mathrm{Cd}$.

Dentre os principais fatores que afetam o sucesso da fitorremediação destacam-se a disponibilidade de plantas com alta produção de biomassa e com capacidade para concentrar quantidades elevadas de metais pesados na parte aérea (Salt et al. 1995). Nas regiões tropicais e subtropicais, as macrófitas aquáticas têm sido freqüentemente usadas no monitoramento de águas poluídas por metais pesados e pesticidas, devido a grande produção de biomassa e abundância (Klumpp et al. 2002). As espécies A. philoxeroides e P. ferrugineum ocorrem naturalmente em grande abundância no rio Cachoeira, onde foram coletadas, especialmente no período de estiagem quando o nível da água torna-se bastante reduzido.

Portanto, as alterações anatômicas e fisiológicas verificadas nas macrófitas aquáticas analisadas neste estudo, quando submetidas a diferentes concentrações de $\mathrm{Cd}$ em solução nutritiva, demonstraram que $P$. ferrugineum é uma espécie mais sensível ao $\mathrm{Cd}$, restringindo, dessa forma, o seu uso na descontaminação de ambientes com altos índices deste elemento metálico. Por outro lado, A. philoxeroides mostrou-se mais tolerante, apresentando alterações apenas em nível celular, acumulando uma quantidade significativa de $\mathrm{Cd}$ em suas raízes. Em estudos anteriores Naqvi \& Rizvi (2000), Naqvi et al. (1993) já haviam constatado a potencialidade de A. philoxeroides na remoção de $\mathrm{Cu}$ e $\mathrm{Cr}$ de solos e águas contaminadas, destacando o seu potencial para acumular $\mathrm{Cd}$ quando cultivada em solos contaminados por este metal. Assim, esta espécie possui potencial para ser utilizada como fitoextratora, devido à sua capacidade de acumular Cd no sistema radicular, sem afetar, consideravelmente, as trocas gasosas foliares.

\section{Agradecimentos}

Os autores agradecem ao Centro de Pesquisas da Comissão Executiva do Plano da Lavoura Cacaueira (CEPLAC) por disponibilizar a casa de vegetação para montagem do experimento; à Fundação de Amparo à
Pesquisa do Estado da Bahia (FAPESB), pela concessão da bolsa de Iniciação Científica à primeira autora; ao Service Central d'Analyses, Lion, França, pelas análises ICP-MS.

\section{Referências bibliográficas}

Brummitt, R.K. \& Powel, C.E. 1992. Authors of plant names. London, Royal Botanic Gardens.

Chen, S.L. \& Kao, C.H. 1995. Prior temperature exposure affects subsequent Cd-induced ethylene production in rice leaves. Plant Science 104: 135-138.

Chugh, L.K. \& Sawhney, S.K. 1999. Photosynthetic activities of Pisum sativum seedlings grown in presence of cadmium. Plant Physiology Biochemistry 37: 297-303.

Dantas, B.F.; Aragão, C.A. \& Alves, J.D. 2001. Cálcio e o desenvolvimento de aerênquimas e atividade de celulase em plântulas de milho submetidas a hipoxia. Scientia Agricola 58: 251-257.

Dixit, V.; Pandey, V. \& Shyam, R. 2001. Differential antioxidative responses to cadmium in roots and leaves of pea (Pisum sativum L. cv. Azad). Journal of Experimental Botany 52: 1101-1109.

Drew, M.C.; He, C.J. \& Morgan, P.W. 2000. Programmed cell death and aerenchyma formation in roots. Trends in Plant Science 5: $123-127$

Fahn, A. 1982. Plant Anatomy. Oxford, Pergamon Press. 544p.

Franceschi, V.R. \& Horner, H.T. 1980. Calcium oxalate crystals in plants. Botany Review 46: 361-427.

Grant, C.A.; Buckley, W.T.; Bailey, L.D. \& Selles, F. 1998. Cadmium accumulation in crops. Canadian Journal of Plant Science 78: $1-17$.

Hoagland, D.R. \& Arnon, D.I. 1950. The water culture method for growing plants without soil. California, University of California Circular, 347.

Hall, J.L. 2002. Cellular mechanisms for heavy metal detoxification and tolerance. Journal of Experimental Botany 53: 1-11.

Houot, V.; Etienne, P.; Petitot, A-S.; Barbier, S.; Blein, J-P. \& Suty, L. 2001. Hydrogen peroxide induces programmed cell death features in cultured tobaco BY-2 cells, in a dose- dependent manner. Journal of Experimental Botany 52: 1721-1730.

Jensen, W.A. 1962. Botanical histochemistry: principes and practice. San Francisco, W.H. Freeman.

Johansen, D.A. 1940. Plant microtechnique. New York, McGrawHill Book Company.

Klumpp, A.; Bauer, K.; Franz-Gerstein, C. \& Menezes, M. 2002. Variation of nutrient and metal concentrations in aquatic macrophytes along the Rio Cachoeira in Bahia (Brazil). Environment International 28: 165-171.

Knecht, J.A.; van Dillen, M.; Koevoets, P.L.M.; Schat, H.; Verkleij, J.A.C. \& Ernst, W.H.O. 1994. Phytochelatins in cadmiumsensitive and cadmium-tolerant Silene vulgaris. Plant Physiology 104: 255-261.

Küpper, H.; Lombi, E.; Zhao, F.J. \& McGrath, S.P. 2000. Cellular compartmentation of cadmium and zinc in relation to other elements in the hyperaccumulator Arabidopsis halleri. Planta 212: $75-84$

Lavid, N.; Barkay, Z. \& Tel-Or, E. 2001a. Accumulation of heavy metals in epidermal glands of the waterlity (Nymphaeaceae). Planta 212: 313-322.

Lavid, N.; Schwartz, A.; Yarden, O. \& Tel-Or, E. 2001b. The involvement of polyphenols and peroxidase activities in heavymetal accumulation by epidermal glands of the waterlity (Nymphaeaceae). Planta 212: 323-331.

Lorenzi, H. 2000. Plantas daninhas do Brasil: terrestres, aquáticas, parasitas e tóxicas. Nova Odessa, Instituto Plantarum. 
MacFarlane, G.R. \& Burchett, M.D. 1999. Zn distribution and excretion in the leaves of the Grey Mangrove Avicennia marina (Forsk.) Veirh. Environmental and Experimental Botany 41: $167-175$.

Malavolta, E. 1994. Fertilizantes e seu impacto ambiental, micronutrientes e metais pesados: Mitos, Mistificação e Fatos. São Paulo, ProduQuímica.

Mazen, A.M.A. \& El Maghraby, O.M.O. 1997. Accumulation of cadmium, lead and strontium, and a role of calcium oxalate in water hyacinth tolerance. Biologia Plantarum 40: 411-117.

Melo, E. 2000. Polygonaceae da cadeia do Espinhaço, Brasil. Acta Botanica Brasilica 14: 273-300.

Mendelssohn, I.A.; Mckee, K.L. \& Kong, T. 2001. A comparison of physiological indicators of sublethal cadmium stress in wetland plants. Environmental and Experimental Botany 46: 263-275.

Metwally, A.; Finkemeier, I.; Georgi, M. \& Diezt, K-J. 2003. Salicylic acid alleviates the cadmium toxicity in barley seedlings. Plant Physiology 132: 272-281.

Naqvi, S.M.; Howell R.D. \& Sholas, M. 1993. Cadmium and lead residues in field-collected red swamp crayfish, Procambarus clarkii and uptake by alligator weed, Alternanthera philoxeroides. Journal Environmental Science Health 28: 473-485.

Naqvi, S.M. \& Rizvi, S.A. 2000. Accumulation of chromium and copper in three different soils and bioaccumulation in an aquatic plant, Alternanthera philoxeroides. Bulletin of Environmental Contamination and Toxicology 65: 55-61.

O’brien, T.P.; Feder, N. \& Mccully, M.E. 1990. Polycromatic staining of plant cell walls by toluidine blue. Protoplasma 59: 368-373.

Oliveira, J.A.; Cambraia, J.; Cano, M.A.O. \& Jordão, C.P. 2001. Absorção e acúmulo de cádmio e seus efeitos sobre o crescimento relativo de plantas de aguapé e de salvínia. Revista Brasileira de Fisiologia Vegetal 13: 329-341.

Poole I. \& Kürschner W. 1999. Stomatal density and index: the practice. Pp. 257-260. In: T.P. Jones \& N.P. Rowe (eds.). Fossil Plants and Spores: modern techniques. London, Geological Society.

Pott, V.J. \& Pott, A. 2000. Plantas Aquáticas do Pantanal. Brasília, EMBRAPA Comunicação para transferência de Tecnologia.

Pilon-Smits, E. 2005. Phytoremediation. Annual Review Plant Biology 56: 15-39.
Psaras, G.K.; Constantinidis, T.H.; Cotsopoulos, B. \& Manetas, Y. 2000. Relative abundace of nickel in the leaf epidermis of eight hyperaccumulators: evidence that the metal is excluded from both guard cells and trichomes. Annals of Botany 86: 73-78.

Salt, D.E.; Prince, R.C.; Pickering, I.J. \& Raskin, I. 1995. Mechanisms of cadmium mobility and accumulation in Indian mustard. Plant Physiology 109: 1427-1433.

Satarug, S.; Baker, J.R.; Urbenjapol, S.; Elkins, M.H.; Reilly, P.E.B.; Williams, D.J. \& Moore, M.R. 2003. A global perspective on cadmium pollution and toxicity innon-occupationally exposed population. Toxicology Letters 137: 65-83.

Schützendübel, A.; Schwanz, P.; Teichmann, T.; Gross. K.; LangenfeldHeyser, R.; Godbold, D.L. \& Polle, A. 2001. Cadmium-induced changes in antioxidative systems, hydrogen peroxide content, and differentiation in scots pine roots. Plant Physiology 127: 887-898.

Soares, C.R.F.S.; Siqueira, J.O.; Carvalho, J.G. \& Moreira, F.M.S. 2005. Fitoxidez de cádmio para Eucalyptus maculata e E. urophylla em solução nutritiva. Revista Árvore 29: 175-183.

Soltan, M.E. \& Rashed, M.N. 2003. Laboratory study on the survival of water hyacinth under several conditions of heavy metal concentrations. Advances in Environmental Research 7: 321-334.

Sridhar, B.B.M.; Diehl, S.V.; Han, F.X.; Monts, D.L. \& Su, Y. 2005. Anatomical changes due to uptake and accumulation of $\mathrm{Zn}$ and $\mathrm{Cd}$ in Indian mustard (Brassica juncea). Environmental and Experimental Botany 54: 131-141.

Sundberg, M.D. 1992. An Introduction to stereological analysis: mophometric techiques for beginning biologists. Pp: 51-72. In: Proceedings of the $6^{\circ}$ Workshop/Conference of the Association for Biology Laboratory Education (ABLE). Canada, University of Newfoundland.

Toppi, L.S.; Lambardi, M.; Pazzagli, L.; Capuggi, G.; Durante, M. \& Gabbrielli, R. 1998. Response to cadmium in carrot in vitro plants and cell suspension cultures. Plant Science 137: 119-129.

Vecchia, F.D.; La Rocca, N.; Moro, I.; De Faveri, S.; Andreoli, C. \& Rascio, N. 2005. Morfhogenetic ultrastructural and physiological damages suffered by submerged leaves of Elodea canadensis exposed to cadmium. Plant Science 168: 329-338.

Zhou, H.; Shi, G.; Du, K.; Xu, Q. \& Xu, N. 2003. Toxic effects of $\mathrm{Cd}^{+2}$ pollution on the biochemical and physiological characters and ultrastructure of Alternanthera philoxeroides. The Journal of Applied Ecology 14: 1581-1584. 